\title{
Corrosion Inhibition of Carbon Steel in HCI Solutions Using Aminopyrimidine Derivatives
}

\author{
S.S. Mahmoud, M.M. Ahmed \\ Chemistry Department, University College of Girls for Arts, Science and Education, Ain Shams \\ University, Heliopolis, Cairo, Egypt
}

Received 18 August 2004; accepted in revised form 2 February 2006

\begin{abstract}
This work aimed to study the corrosion inhibition of carbon steel in $2 \mathrm{M} \mathrm{HCl}$ solutions using some aminopyrimidine derivatives. In this investigation the techniques of measurements were: weight loss, linear polarization, impedance and corrosion penetration. The inhibitory effect of the investigated compounds resulted from their adsorption onto the carbon steel. Their adsorption on the metallic surface obeyed Frumkin's model of adsorption. The inhibition efficiency of the compound greatly depends on the electron density on the molecules, which in turn depends on its structure. The values of activation energy were determined in $2 \mathrm{M} \mathrm{HCl}$ in the absence and in the presence of inhibitors. The presence of inhibitors increases the values of the activation energy of corrosion. The adsorption of these compounds onto the metallic surface occurs via the $\mathrm{N}$-atoms of amino-groups, O-atoms of hydroxy-groups, and Satoms of mercapto group present in the compound. For this reason the inhibitory effect of the inhibitors varied according to the number and nature of adsorption centers in the molecules.
\end{abstract}

Keywords: corrosion penetration, carbon steel, aminopyrimidine derivatives, linear polarization, impedance.

\section{Introduction}

The carbon steel is used as essential part in the manufacturing of installations used in the petroleum and other industries. The use of inhibitors is one of the most practical methods for protection against metallic corrosion, especially in acidic media. The action of inhibition of the steel corrosion in acidic media by various organic compounds has been widely studied [1-5]. Hydrochloric and sulphuric acids are often used in the pickling of steel and ferrous alloys.

\footnotetext{
*Corresponding author. E-mail address: drsohairr@hotmail.com
} 
Inhibitors find application in pickling, cleaning and acid descaling processes. In general, organic compounds such as amines, acetylenic alcohols, heterocyclic compounds, etc., have found use as inhibitors in industrial applications [6-16].

Most of the well known acid inhibitors are organic compounds containing nitrogen, sulphur and oxygen. The existing data show that most organic inhibitors act by adsorption on the metal surface. This phenomenon is influenced by the nature and surface charge of metal, by the aggressive media and by chemical structure of the inhibitors.

The aim of this paper is to study the inhibiting action of new organic compounds containing nitrogen, oxygen and sulphur and heterocyclic aromatic ring. The electrochemical behavior of carbon steel in $\mathrm{HCl}$ media in the absence and in the presence of inhibitors has been studied by different techniques.

\section{Experimental}

Carbon steel coupons containing $0.7 \% \mathrm{C}, 0.15 \% \mathrm{Si}, 0.4 \% \mathrm{Mn}, 0.0017 \% \mathrm{P}$, and $0.0189 \% \mathrm{~S}$, and the remainder iron, were used for gravimetric and electrochemical measurements. These coupons were provided from Rose Corrosion Services LTD, Hambridge Lane, Newbury Berk, UK, and having the dimensions $7.4 \times 2.2 \times 0.4 \mathrm{~cm}$. The corrosion rate of this alloy was determined by weight loss, linear polarization, and impedance and corrosion penetration measurements. For weight loss measurements, the samples have the dimensions of $3 \times 3 \times 0.4 \mathrm{~cm}$. For the electrochemical measurements electrodes measuring 2 $\times 1 \times 0.4 \mathrm{~cm}$ were used. For electrical connection a stout copper wire lead was fixed at one end of the electrode by mechanical jamming. A platinum sheet of $1.5 \times 1.5 \mathrm{~cm}$ and a saturated calomel electrode (SCE) were used as auxiliary and reference electrodes, respectively. The current values used in electrochemical measurements were derived from a constant current unit $(2 \mu \mathrm{A}-200 \mathrm{~mA}), \mathrm{LG}$ Precision Co, LTD, Korea. The potential of the working electrode relative to (SCE) was measured on digital multimeter model 1008, Kyoritsu (Japan). Impedance measurements were carried out using the impedance measurement system IM6 Zahner Electric (Meßtechnik, Germany). Impedance measurements were conducted with excitation amplitude of $10 \mathrm{mV}$ peak to peak and the frequency domain from $0.1 \mathrm{~Hz}$ to $100 \mathrm{kHz}$.

The organic inhibitors used in this study were selected from aminopyrimidine derivatives (BDH grade). These compounds have the structures:

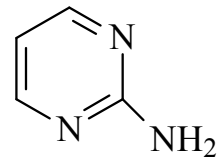

2-aminopyrimidine (I)<smiles>Oc1cc(O)ncn1</smiles> 
<smiles>Nc1ccnc(N)n1</smiles>

2,4-diaminopyrimidine (III)<smiles>Nc1cc(O)nc(N)n1</smiles>

2,4-diamino-6-hydroxypyrimidine (IV)<smiles>Nc1cc(N)nc(N)n1</smiles>

2,4,6-triaminopyrimidine (V)<smiles>Nc1cc(N)nc(S)n1</smiles>

4,6-diamino-2-mercaptopyrimidine (VI)

Prior to the measurements, the samples and electrodes were polished with emery paper up to 4/0, washed thoroughly with distilled water, rinsed in acetone and dried in air. The aggressive solutions were prepared by dilution of analytical $37 \%$ $\mathrm{HCl}$ with doubly distilled water.

\section{Results and discussion}

\section{Weight loss measurements}

The results of these measurements are shown in Table 1 for the corrosion of carbon steel in $2 \mathrm{M} \mathrm{HCl}$ in the absence and in the presence of different concentrations of the investigated organic compounds (I-VI), at a temperature of $25{ }^{\circ} \mathrm{C}$. The values of the inhibition efficiency, I\%, are calculated from the corrosion rate data, Table 1 , by using the following equation, and listed in Table 2.

$$
I \%=\left[1-\frac{\left(R_{w}\right)_{\text {inh }}}{\left(R_{w}\right)_{\text {free }}}\right] \times 100
$$

where $\left(R_{\mathrm{w}}\right)_{\text {free }}$ and $\left(\mathrm{R}_{\mathrm{w}}\right)_{\text {inh }}$ are the corrosion rate $\left(\mathrm{mg} / \mathrm{cm}^{2} / \mathrm{h}\right)$ in the absence and in the presence of inhibitor, respectively.

Fig. 1 represents the variation of the inhibition efficiency, I\%, as a function of the inhibitors concentration. The plots of this figure have S-shape and the inhibition 
efficiency of the investigated organic compounds increases according to the order: I $<$ II $<$ III $<$ IV $<$ V $<$ VI.

Table 1. Corrosion rate $\left(R_{\mathrm{w}}\right)$ obtained from the weight loss measurements for carbon steel in $2 \mathrm{M} \mathrm{HCl}$ in the absence and in the presence of different concentrations of organic compounds at $25^{\circ} \mathrm{C}$.

\begin{tabular}{ccccccc}
\hline $\begin{array}{c}\text { Conc. } \\
(\mathrm{M})\end{array}$ & \multicolumn{7}{c}{$\mathrm{R}_{\mathrm{w}}\left(\mathrm{mg} \mathrm{cm}^{-2} \mathrm{~h}^{-1}\right)$} \\
\cline { 2 - 7 } & $\mathrm{I}$ & $\mathrm{II}$ & $\mathrm{III}$ & $\mathrm{IV}$ & $\mathrm{V}$ & $\mathrm{VI}$ \\
\hline 0.00 & 8.00 & 8.00 & 8.00 & 8.00 & 8.00 & 8.00 \\
$1 \times 10^{-6}$ & 6.24 & 6.08 & 5.88 & 5.60 & 5.20 & 4.80 \\
$1 \times 10^{-5}$ & 5.60 & 5.36 & 5.20 & 4.96 & 4.80 & 4.16 \\
$1 \times 10^{-4}$ & 4.00 & 3.68 & 3.48 & 3.28 & 3.04 & 2.56 \\
$1 \times 10^{-3}$ & 2.40 & 2.00 & 1.76 & 1.52 & 1.20 & 0.80 \\
$1 \times 10^{-2}$ & 2.24 & 1.84 & 1.60 & 1.28 & 0.80 & 0.40 \\
\hline
\end{tabular}

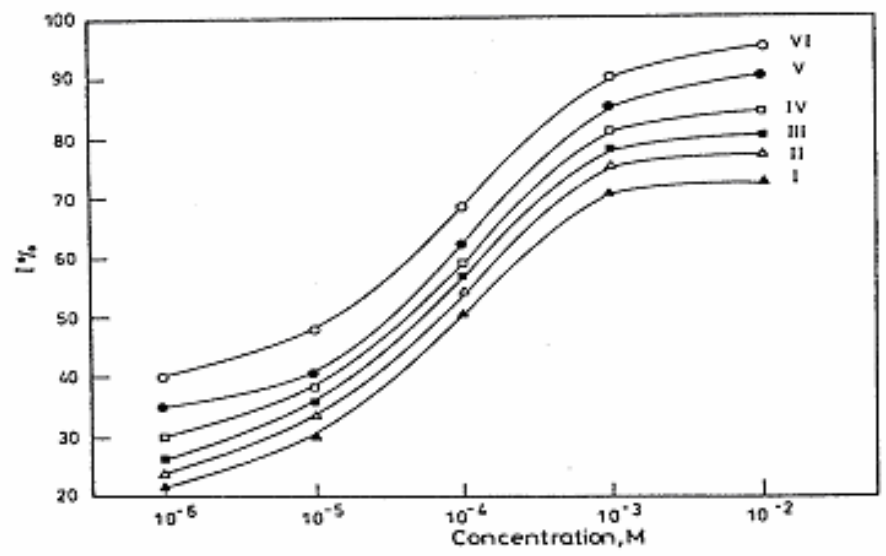

Figure 1. Effect of inhibitors concentration on the inhibition efficiency at $25^{\circ} \mathrm{C}$ (weight loss measurements).

\section{Linear polarization measurements}

Fig. 2 represents the plot of potential E, versus current density, i, for the working electrode in pure $2 \mathrm{M} \mathrm{HCl}$ solution and in the presence of different concentrations of compound I at a temperature of $25{ }^{\circ} \mathrm{C}$. Similar plots are obtained for the other organic compounds (II-VI) and not shown. Values of the linear polarization resistance, $R_{p}$, are deduced from the slopes, $(\Delta E / \Delta i)$, of straight lines of Fig. 2 and similar ones, and listed in Table 3 for the investigated organic compounds (I-VI). The values of the inhibition efficiency, I\%, are calculated from $\mathrm{R}_{\mathrm{p}}$ data, (Table 3 ), by using the following equation:

$$
I \%=\left[1-\frac{\left(R_{p}\right)_{\text {free }}}{\left(R_{p}\right)_{\text {inh }}}\right] \times 100
$$


where $\left(R_{p}\right)_{\text {free }}$ and $\left(R_{p}\right)_{\text {inh }}$ are the linear polarization resistance in pure $2 \mathrm{M} \mathrm{HCl}$ and in the presence of the inhibitor, respectively. The calculated values of $\mathrm{I} \%$ are listed in Table 4 for the different concentrations of the investigated organic compounds (I-VI).

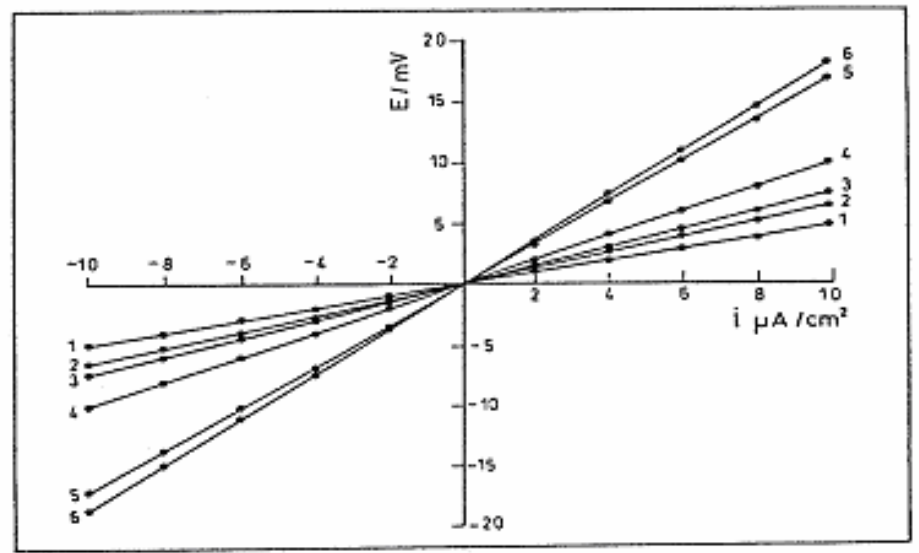

Figure 2. Plots of potential versus current for $\mathrm{C}$-steel in $2 \mathrm{M} \mathrm{HCl}$ in the absence and in the presence of different concentrations of compound (I) at $25^{\circ} \mathrm{C}$. 1 - blank, $2-1 \times 10^{-6}$ M, 3- $1 \times 10^{-5} \mathrm{M}, 4-1 \times 10^{-4} \mathrm{M}, 5-1 \times 10^{-3} \mathrm{M}, 6-1 \times 10^{-2} \mathrm{M}$.

Table 2. Inhibition efficiency (I\%) obtained from the weight loss measurements $\left(\mathrm{R}_{\mathrm{w}}\right)$.

\begin{tabular}{ccccccc}
\hline Conc. & \multicolumn{7}{c}{ I\% } \\
\cline { 2 - 7 }$(\mathrm{M})$ & I & II & III & IV & V & VI \\
\hline $1 \times 10^{-6}$ & 22 & 24 & 26.5 & 30 & 35 & 40 \\
$1 \times 10^{-5}$ & 30 & 33 & 35.0 & 38 & 40 & 48 \\
$1 \times 10^{-4}$ & 50 & 54 & 56.5 & 59 & 62 & 68 \\
$1 \times 10^{-3}$ & 70 & 75 & 78 & 81 & 85 & 90 \\
$1 \times 10^{-2}$ & 72 & 77 & 80 & 84 & 90 & 95 \\
\hline
\end{tabular}

Fig. 3 represents the effect of the inhibitor concentration on the inhibition efficiency of the investigated compounds. The plots of this figure have S-shape and the inhibition efficiency of these compounds increases according to the order: I $<$ II $<$ III $<$ IV $<$ V $<$ VI. This order is the same as that obtained by weight loss measurements.

\section{Impedance measurements}

Figs. 4-9 represent the impedance diagrams (Nyquist plots) for the carbon steel electrode in $2 \mathrm{M} \mathrm{HCl}$ and in the presence of increasing concentration of the investigated organic compounds (I-VI), respectively, at $25{ }^{\circ} \mathrm{C}$. The charge transfer resistance values $\left(\mathrm{R}_{\mathrm{t}}\right)$ are calculated from the difference in impedance at lower and higher frequencies [17]. 
Table 3. Data of linear polarization measurements $\left(R_{p}\right)$ for carbon steel in $2 \mathrm{M} \mathrm{HCl}$ in the absence and in the presence of different concentrations of organic compounds at 25 ${ }^{\circ} \mathrm{C}$.

\begin{tabular}{ccccccc}
\hline Conc. & \multicolumn{6}{c}{$\mathrm{R}_{\mathrm{p}}\left(\Omega . \mathrm{cm}^{-2}\right)$} \\
\cline { 2 - 7 }$(\mathrm{M})$ & $\mathrm{I}$ & $\mathrm{II}$ & $\mathrm{III}$ & $\mathrm{IV}$ & $\mathrm{V}$ & $\mathrm{VI}$ \\
\hline 0.00 & 500 & 500 & 500 & 500 & 500 & 500 \\
$1 \times 10^{-6}$ & 649.35 & 666.67 & 684.93 & 719.42 & 781.25 & 847.48 \\
$1 \times 10^{-5}$ & 724.64 & 769.23 & 787.4 & 819.67 & 847.46 & 990.10 \\
$1 \times 10^{-4}$ & 1000 & 1111.11 & 1190.48 & 1250 & 1538.46 & 1639.34 \\
$1 \times 10^{-3}$ & 1724.14 & 2083.33 & 2380.95 & 2777.78 & 3571.43 & 6250 \\
$1 \times 10^{-2}$ & 1851.85 & 2272.73 & 2702.7 & 3333.33 & 5555.56 & 12500 \\
\hline
\end{tabular}

Table 4. Inhibition efficiency ( $\mathrm{I} \%$ ) obtained from $\mathrm{R}_{\mathrm{p}}$ data.

\begin{tabular}{ccccccc}
\hline Conc. & \multicolumn{7}{c}{ I\% } \\
\cline { 2 - 7 }$(\mathrm{M})$ & I & II & III & IV & V & VI \\
\hline $1 \times 10^{-6}$ & 23 & 25 & 27 & 30.5 & 36 & 41 \\
$1 \times 10^{-5}$ & 31 & 35 & 36.5 & 39 & 41 & 49.5 \\
$1 \times 10^{-4}$ & 50 & 55 & 58 & 60 & 62.5 & 69.5 \\
$1 \times 10^{-3}$ & 71 & 76 & 79 & 82 & 86 & 92 \\
$1 \times 10^{-2}$ & 73 & 78 & 81.5 & 85 & 91 & 96 \\
\hline
\end{tabular}

The double layer capacitance, $\mathrm{C}_{\mathrm{dl}}$, was determined from the frequency, $\mathrm{f}$, at which $\mathrm{t}_{\mathrm{i}}$ was maximum, using the relationship:

$$
f\left(-Z_{i m, \max }\right)=\left(2 \pi C_{d 1} R_{t}\right)^{-1}
$$

The inhibition efficiency, I\%, of the working electrode is calculated from the charge transfer resistance, $\mathrm{R}_{\mathrm{t}}$, using the equation:

$$
I \%=\frac{R_{t \text { corr }}^{-1}-R_{\text {tcorr }(\text { inh })}^{-1}}{R_{\text {tcorr }}^{-1}} \times 100
$$

where $R_{t \text { corr }}$ and $R_{t \text { corr(inh) }}$ are the charge transfer resistance values in the absence and in the presence of the inhibitor, respectively. 


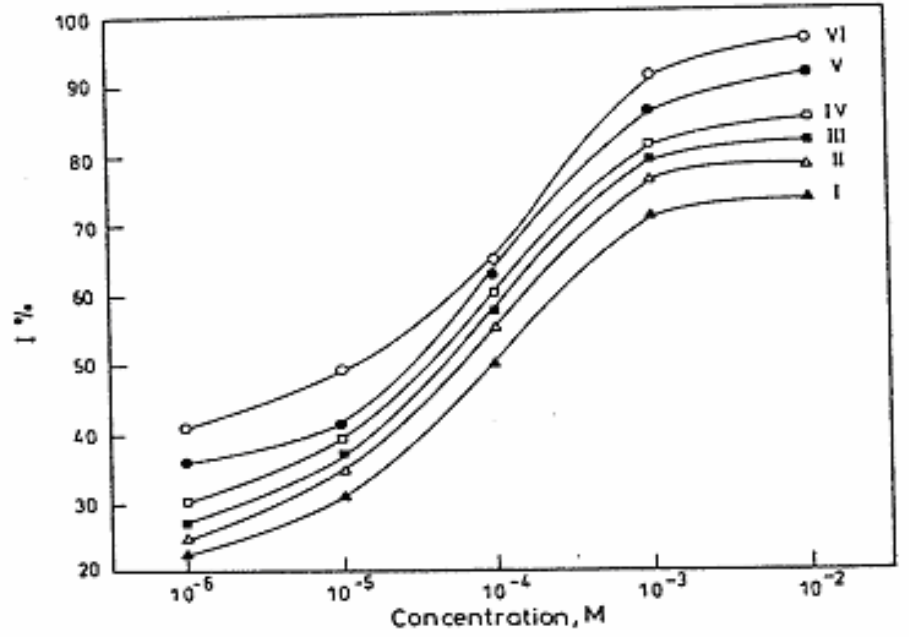

Figure 3. Effect of inhibitors concentration on the inhibition efficiency at $25^{\circ} \mathrm{C}$ (linear polarization measurements).

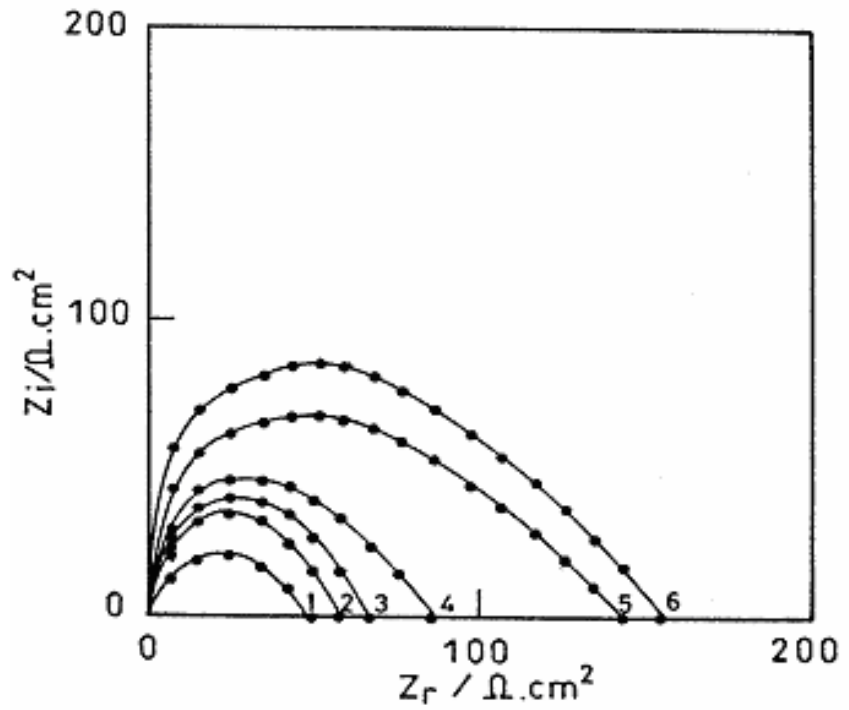

Figure 4. Nyquist plot for $\mathrm{C}$-steel in $2 \mathrm{M} \mathrm{HCl}$ in the absence and in the presence of different concentrations of compound (I) at $20^{\circ} \mathrm{C}$. 1 - blank, $2-1 \times 10^{-6} \mathrm{M}, 3-1 \times 10^{-5} \mathrm{M}$, 4- $1 \times 10^{-4} \mathrm{M}, 5-1 \times 10^{-3} \mathrm{M}, 6-1 \times 10^{-2} \mathrm{M}$.

The values of $\mathrm{R}_{\mathrm{t}}, \mathrm{C}_{\mathrm{dl}}$ and $\mathrm{I} \%$ derived from impedance measurements are shown in Tables 5-7, for the investigated organic compounds (I-VI). The results of these tables indicate that as the inhibitors concentration increases, the values of $R_{t}$ and $\mathrm{I} \%$ increase, but the values of $\mathrm{C}_{\mathrm{dl}}$ decrease. This indicates the occurrence of adsorption of inhibitors on the electrode surface. 


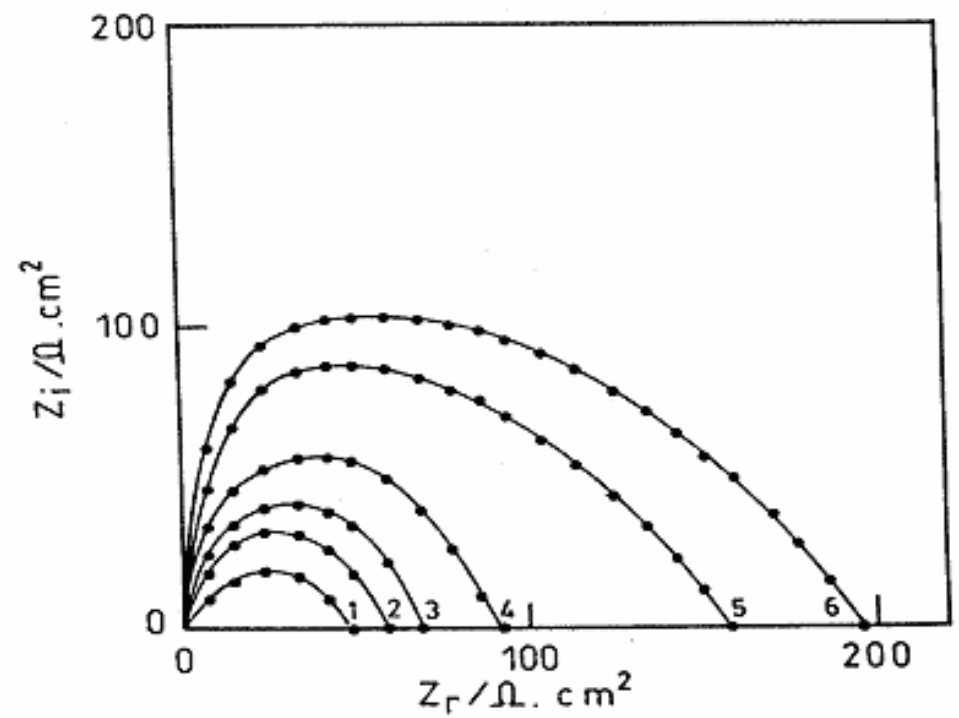

Figure 5. Nyquist plot for $\mathrm{C}$-steel in $2 \mathrm{M} \mathrm{HCl}$ in the absence and in the presence of different concentrations of compound (II) at $25^{\circ} \mathrm{C}$. 1 - blank, $2-1 \times 10^{-6} \mathrm{M}, 3-1 \times 10^{-5} \mathrm{M}$, 4- $1 \times 10^{-4} \mathrm{M}, 5-1 \times 10^{-3} \mathrm{M}, 6-1 \times 10^{-2} \mathrm{M}$.

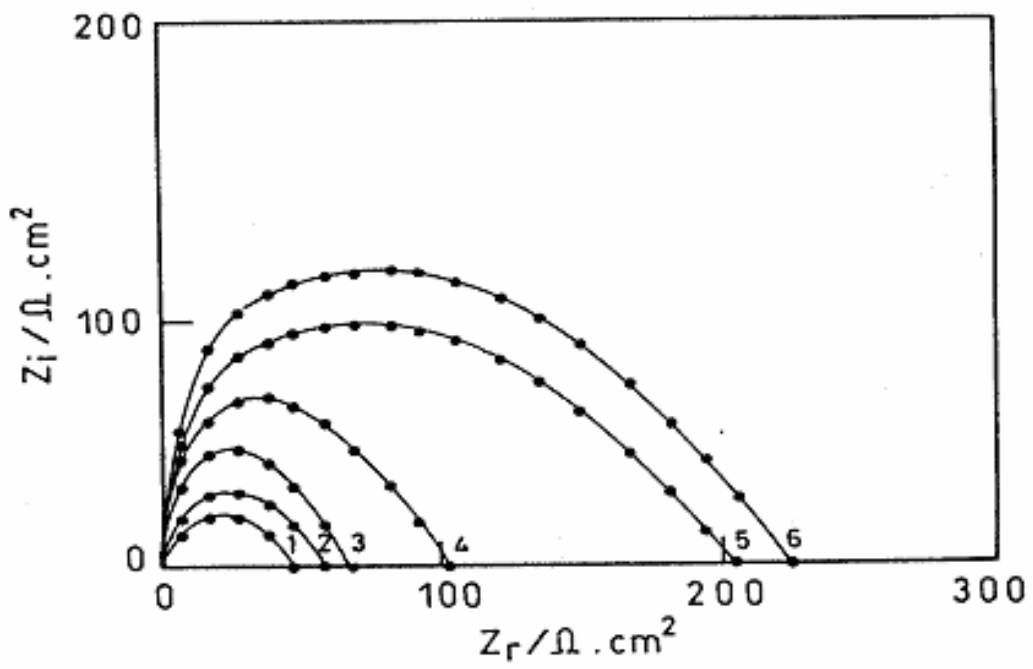

Figure 6. Nyquist plot for $\mathrm{C}$-steel in $2 \mathrm{M} \mathrm{HCl}$ in the absence and in the presence of different concentrations of compound (III) at $20^{\circ} \mathrm{C}$. 1- blank, $2-1 \times 10^{-6} \mathrm{M}, 3-1 \times 10^{-5} \mathrm{M}$, 4- $1 \times 10^{-4} \mathrm{M}, 5-1 \times 10^{-3} \mathrm{M}, 6-1 \times 10^{-2} \mathrm{M}$.

Fig. 10 represents the effect of the inhibitor concentration on the inhibition efficiency of the investigated compounds. The obtained plots have S-shape and the inhibition efficiency of these compounds increases according to the order: I $<$ II $<$ III $<$ IV $<$ V $<$ VI. This order is the same as that obtained by weight loss and linear polarization measurements. 


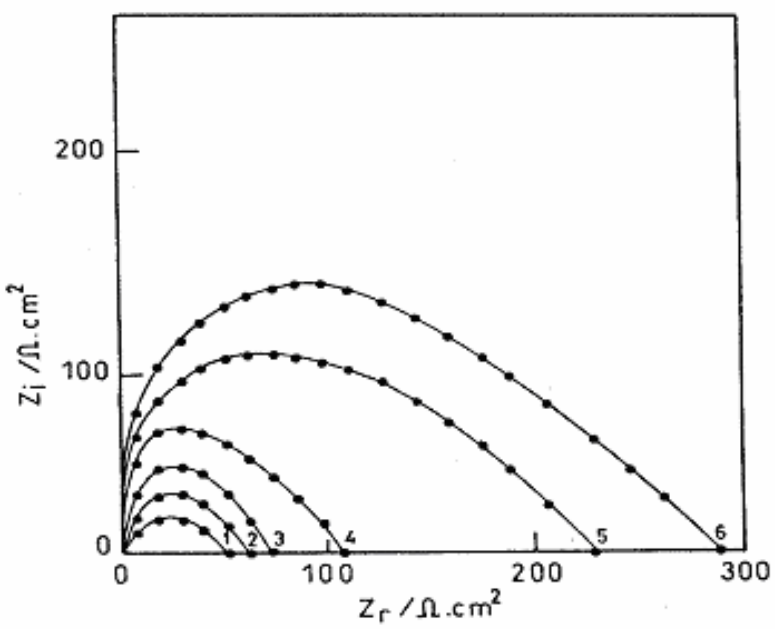

Figure 7. Nyquist plot for $\mathrm{C}$-steel in $2 \mathrm{M} \mathrm{HCl}$ in the absence and in the presence of different concentrations of compound (IV) at $20^{\circ} \mathrm{C}$. 1 - blank, $2-1 \times 10^{-6} \mathrm{M}, 3-1 \times 10^{-5} \mathrm{M}$, 4- $1 \times 10^{-4} \mathrm{M}, 5-1 \times 10^{-3} \mathrm{M}, 6-1 \times 10^{-2} \mathrm{M}$.

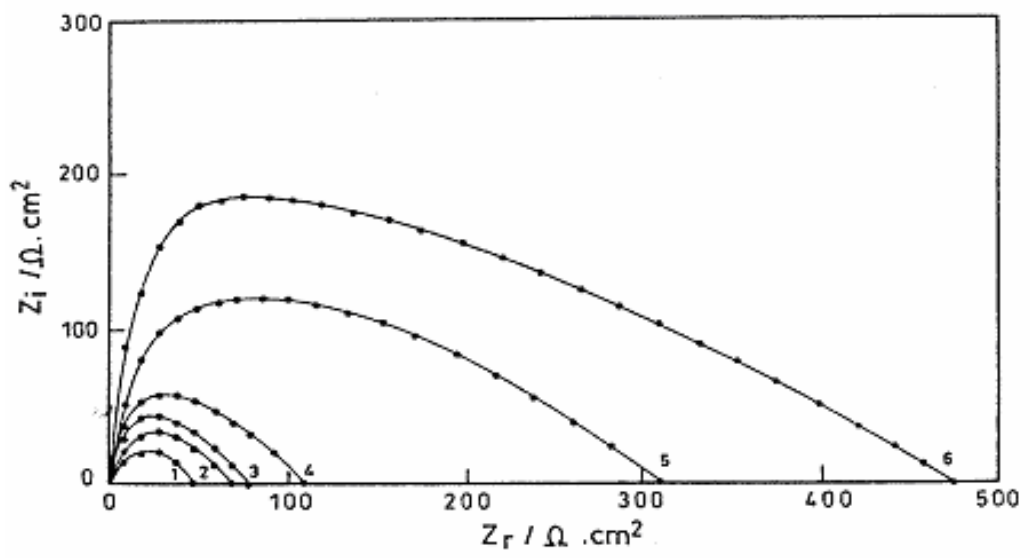

Figure 8. Nyquist plot for $\mathrm{C}$-steel in $2 \mathrm{M} \mathrm{HCl}$ in the absence and in the presence of different concentrations of compound (V) at $20^{\circ} \mathrm{C}$. 1 - blank, $2-1 \times 10^{-6} \mathrm{M}, 3-1 \times 10^{-5} \mathrm{M}$, 4- $1 \times 10^{-4} \mathrm{M}, 5-1 \times 10^{-3} \mathrm{M}, 6-1 \times 10^{-2} \mathrm{M}$.

\section{Corrosion penetration}

The corrosion penetration (CP) of the carbon steel can be calculated from the weight loss measurements using the equation [18]:

$$
\mathrm{CP}=\mathrm{w} / \mathrm{Ad}
$$

where $\mathrm{w}$ is the weight loss in $(\mathrm{g}), \mathrm{A}$ is the surface area of carbon steel specimen $\left(\mathrm{cm}^{2}\right)$ and $\mathrm{d}$ is the density $\left(\mathrm{g} / \mathrm{cm}^{3}\right)$ of the carbon steel $(\cong 7.88)$. The values of corrosion penetration (CP) are calculated by equation (5) for the carbon steel specimens in $2 \mathrm{M} \mathrm{HCl}$ in the absence and in the presence of $10^{-3} \mathrm{M}$ of inhibitors at different immersion time $(1,2,3,4,5$ hours $)$ at $25{ }^{\circ} \mathrm{C}$ and listed in Table 8. 


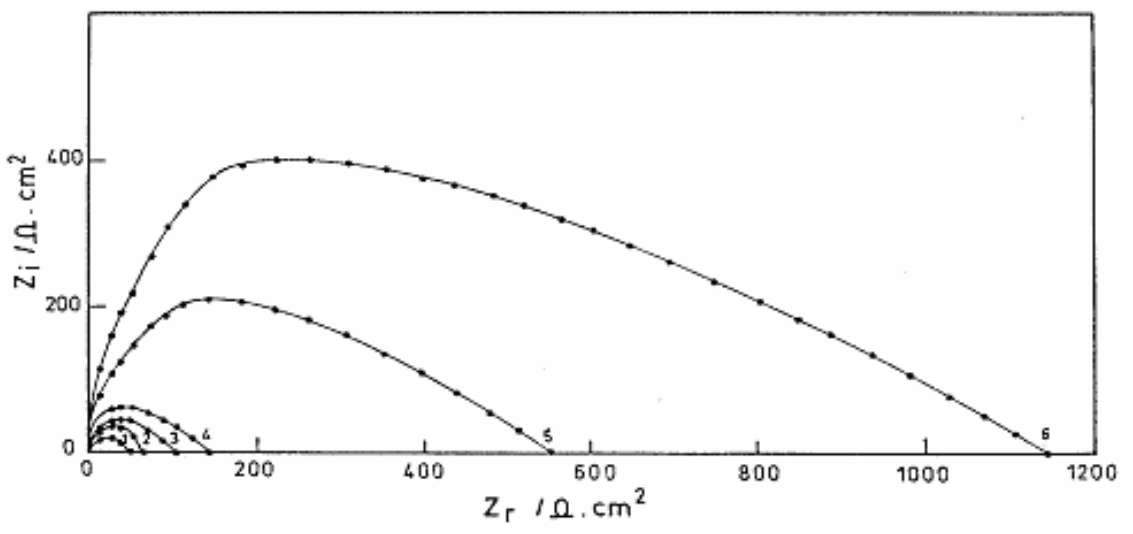

Figure 9. Nyquist plot for $\mathrm{C}$-steel in $2 \mathrm{M} \mathrm{HCl}$ in the absence and in the presence of different concentrations of compound (VI) at $20^{\circ} \mathrm{C}$. 1 - blank, $2-1 \times 10^{-6} \mathrm{M}, 3-1 \times 10^{-5} \mathrm{M}$, 4- $1 \times 10^{-4} \mathrm{M}, 5-1 \times 10^{-3} \mathrm{M}, 6-1 \times 10^{-2} \mathrm{M}$.

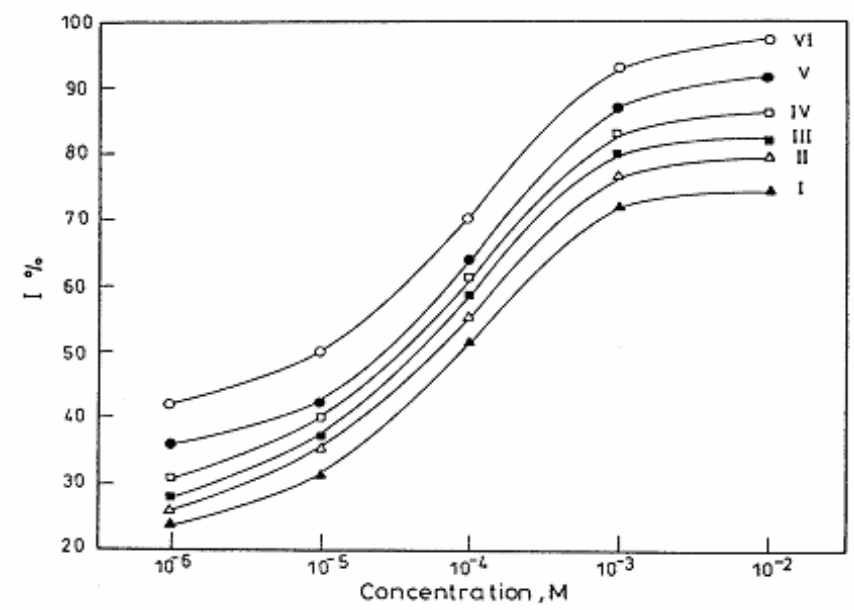

Figure 10. Effect of inhibitors concentration on the inhibition efficiency at $25{ }^{\circ} \mathrm{C}$ (impedance measurements).

Table 5. Data of impedance measurements $\left(\mathrm{R}_{\mathrm{t}}\right)$ for carbon steel in $2 \mathrm{M} \mathrm{HCl}$ in the absence and in the presence of different concentrations of organic compounds at $25^{\circ} \mathrm{C}$.

\begin{tabular}{|c|c|c|c|c|c|c|}
\hline \multirow{2}{*}{$\begin{array}{c}\text { Conc. } \\
\text { (M) }\end{array}$} & \multicolumn{6}{|c|}{$\mathrm{R}_{\mathrm{t}}\left(\Omega \cdot \mathrm{cm}^{2}\right)$} \\
\hline & I & II & III & IV & $\mathrm{V}$ & VI \\
\hline 0.00 & 40 & 40 & 40 & 40 & 40 & 40 \\
\hline $1 \times 10^{-6}$ & 52.63 & 54.10 & 55.17 & 57.97 & 63 & 68.38 \\
\hline $1 \times 10^{-5}$ & 59.70 & 62.02 & 63.49 & 66.67 & 68.97 & 80 \\
\hline $1 \times 10^{-4}$ & 81.63 & 88.89 & 96.385 & 102.56 & 108.11 & 133.33 \\
\hline $1 \times 10^{-3}$ & 140.35 & 170.213 & 200 & 228.57 & 307.69 & 571.43 \\
\hline $1 \times 10^{-2}$ & 150.94 & 190.476 & 222.22 & 285.74 & 470.59 & 1142.86 \\
\hline
\end{tabular}


Table 6. Data of impedance measurements $\left(\mathrm{C}_{\mathrm{dl}}\right)$ for carbon steel in $2 \mathrm{M} \mathrm{HCl}$ in the absence and in the presence of different concentrations of organic compounds at $25{ }^{\circ} \mathrm{C}$.

\begin{tabular}{ccccccc}
\hline Conc. & \multicolumn{5}{c}{$\mathrm{C}_{\mathrm{dl}}\left(\mu \mathrm{F} . \mathrm{cm}^{-2}\right)$} \\
\cline { 2 - 7 }$(\mathrm{M})$ & $\mathrm{I}$ & $\mathrm{II}$ & $\mathrm{III}$ & $\mathrm{IV}$ & $\mathrm{V}$ & $\mathrm{VI}$ \\
\hline 0.00 & 3981 & 3981 & 3981 & 3981 & 3981 & 3981 \\
$1 \times 10^{-6}$ & 1917 & 1839.8 & 1789.8 & 1568.97 & 1444.44 & 1153.9 \\
$1 \times 10^{-5}$ & 1327 & 1284.3 & 1044.95 & 990.36 & 1099.03 & 796.25 \\
$1 \times 10^{-4}$ & 809.20 & 650.70 & 471.5 & 441.75 & 453.70 & 368.42 \\
$1 \times 10^{-3}$ & 289.6 & 208.17 & 159.25 & 126.44 & 82.73 & 26.56 \\
$1 \times 10^{-2}$ & 254.13 & 160.34 & 114.67 & 74.24 & 36.238 & 6.97 \\
\hline
\end{tabular}

The results of Table 8 show a non-linear evolution of $\mathrm{CP}$ with time; this would indicate that the values of $\mathrm{R}_{\mathrm{w}}$ depend on the period considered for the weight loss measurements. This may be explained by the fact that with the increase of the period of the weight loss, the dissolution of more iron from the metallic surface occurs. This process gives rise to the enrichment of the metallic surface with carbon, which greatly affects the rate of corrosion $\left(R_{w}\right)$ and may slowdown this rate.

Table 7. Inhibition efficiency (I\%) calculated from the impedance measurements.

\begin{tabular}{ccccccc}
\hline Conc. & \multicolumn{7}{c}{$\mathrm{I} \%$} \\
\cline { 2 - 7 }$(\mathrm{M})$ & $\mathrm{I}$ & $\mathrm{II}$ & $\mathrm{III}$ & $\mathrm{IV}$ & $\mathrm{V}$ & $\mathrm{VI}$ \\
\hline $1 \times 10^{-6}$ & 24 & 26 & 27.5 & 31 & 36.5 & 41.5 \\
$1 \times 10^{-5}$ & 32 & 35.5 & 37 & 40 & 42 & 50 \\
$1 \times 10^{-4}$ & 51 & 55 & 58.5 & 61 & 63 & 70 \\
$1 \times 10^{-3}$ & 71.5 & 76.5 & 80 & 82.5 & 87 & 93 \\
$1 \times 10^{-2}$ & 73.5 & 79 & 82 & 86 & 91.5 & 96.5 \\
\hline
\end{tabular}

Fig. 11 represents the plots of the corrosion penetration $(\mathrm{CP})$ versus the square root of immersion time $\left(\mathrm{t}^{1 / 2}\right)$ for $\mathrm{C}$-steel in $2 \mathrm{M} \mathrm{HCl}$ in the absence and in the presence of $10^{-3} \mathrm{M}$ of inhibitors at $25{ }^{\circ} \mathrm{C}$. The straight lines of Fig. 11 indicate that the corrosion reaction of carbon steel in $2 \mathrm{M} \mathrm{HCl}$ in the absence and in the presence of the inhibitors follows the parabolic rate low as in the following equation:

$$
\mathrm{X}=\mathrm{kt}^{1 / 2}
$$

where $\mathrm{X}$ is the measure of corrosion extent (i.e., CP), $t$ is the immersion time, and $\mathrm{k}$ is the parabolic rate constant $\left(\mathrm{cm} \cdot \mathrm{h}^{-1 / 2}\right)$. The values of $\mathrm{k}$ are deduced from 
the slopes of the straight lines of Fig. 11 for the carbon steel in $2 \mathrm{M} \mathrm{HCl}$ in the absence and in the presence of $10^{-3} \mathrm{M}$ of the inhibitors and listed in Table 8 . It is clear from the plots of Fig. 11 and data of Table 8 that the presence of the investigated organic compounds in $2 \mathrm{M} \mathrm{HCl}$ greatly decreases the values of $\mathrm{CP}$ and $\mathrm{k}$ according to the order: $\mathrm{I}>\mathrm{II}>\mathrm{III}>\mathrm{IV}>\mathrm{V}>\mathrm{VI}$. This means that these compounds have high inhibiting efficiency, which increases according to the order: $\mathrm{I}<\mathrm{II}<\mathrm{III}<\mathrm{IV}<\mathrm{V}<\mathrm{VI}$. This order is the same as that obtained by the previously mentioned determinations, indicating the suitability of this method for the evaluation of the corrosion extent in the absence and in the presence of the inhibitors.

Table 8. Data of corrosion penetration (CP) of carbon steel in $2 \mathrm{M} \mathrm{HCl}$ in the absence and in the presence of $10^{-3} \mathrm{M}$ of the inhibitors at different immersion times and at $25^{\circ} \mathrm{C}$.

\begin{tabular}{cccccccc}
\hline $\begin{array}{c}\text { Time } \\
(\mathrm{h})\end{array}$ & blank & I & II & III & IV & V & VI \\
\hline 1 & $1.015 \times 10^{-3}$ & $3.046 \times 10^{-4}$ & $2.540 \times 10^{-4}$ & $2.230 \times 10^{-4}$ & $1.930 \times 10^{-4}$ & $1.523 \times 10^{-4}$ & $1.015 \times 10^{-4}$ \\
2 & $2.030 \times 10^{-3}$ & $6.091 \times 10^{-4}$ & $5.076 \times 10^{-4}$ & $4.467 \times 10^{-4}$ & $3.858 \times 10^{-4}$ & $3.046 \times 10^{-3}$ & $2.030 \times 10^{-4}$ \\
3 & $2.800 \times 10^{-3}$ & $9.137 \times 10^{-4}$ & $7.600 \times 10^{-4}$ & $6.700 \times 10^{-4}$ & $5.790 \times 10^{-4}$ & $4.570 \times 10^{-4}$ & $3.046 \times 10^{-4}$ \\
4 & $3.500 \times 10^{-3}$ & $1.100 \times 10^{-3}$ & $9.000 \times 10^{-4}$ & $7.800 \times 10^{-4}$ & $7.000 \times 10^{-4}$ & $5.800 \times 10^{-4}$ & $3.900 \times 10^{-4}$ \\
5 & $4.000 \times 10^{-3}$ & $1.300 \times 10^{-3}$ & $1.050 \times 10^{-3}$ & $9.000 \times 10^{-4}$ & $8.400 \times 10^{-4}$ & $6.500 \times 10^{-4}$ & $4.500 \times 10^{-4}$ \\
$\mathrm{~K} /\left(\mathrm{cm} \cdot \mathrm{h}^{-1 / 2}\right)$ & $2.400 \times 10^{-3}$ & $8.320 \times 10^{-4}$ & $6.460 \times 10^{-4}$ & $5.570 \times 10^{-4}$ & $5.070 \times 10^{-4}$ & $4.030 \times 10^{-4}$ & $2.820 \times 10^{-4}$ \\
\hline
\end{tabular}

The results of Figs. 1, 3 and 10 indicate that the inhibition efficiency slightly increases with the increase of the inhibitor concentration, and then greatly increases reaching a limiting value (i.e., the curves have S-shape). It can be proposed that in these media there is a competition between the active ions such as $\mathrm{Cl}^{-}$, and the inhibitor molecules for the adsorption onto the metallic surface. The adsorbability of each of them greatly depends on their relative concentrations. This means that the inhibitive effect of the organic molecules depends on the concentration of $\mathrm{Cl}^{-}$, which decreases with increasing the ability of the inhibitor to form a protective layer on the metal surface.

The obtained results indicated that the investigated compounds, aminopyrimidine derivatives, have a significant effect. This was conferred by the presence of electron donor atoms such as $\mathrm{N}$ and /or $\mathrm{S}$ in the organic compound. The presence of free electron pairs in these atoms plays the major role in the organic compound on the metallic surface.

The relation between $(\theta)$ and $\log \mathrm{C}$ had the character of an S-shaped adsorption isotherm, Fig. 12. This showed that the investigated inhibitors were adsorbed onto the metallic surface according to the Frumkin isotherm [19]

$$
\theta(1-\theta)^{-1} \exp (-f C)=K C
$$


where $\mathrm{K}$ is the equilibrium constant of adsorption, $\mathrm{f}$ is a function of adsorption energy, $\theta$ is the surface coverage, and $\mathrm{C}$ is the inhibitor concentration. The value of $\theta$ can be calculated from $\mathrm{I} \%(\theta=$ inhibition efficiency $/ 100)$.

To determine the activation energies of the corrosion process, the weight loss measurements were taken at temperatures of $25,35,45$ and $55{ }^{\circ} \mathrm{C}$ in pure $2 \mathrm{M}$ $\mathrm{HCl}$ and in the presence of $10^{-3} \mathrm{M}$ of the investigated inhibitors. Fig. 13 shows Arrhenius plots for the corrosion rate, $\mathrm{R}_{\mathrm{w}}$, in pure $2 \mathrm{M} \mathrm{HCl}$ and in the presence of $10^{-3} \mathrm{M}$ of the inhibitors. The values of apparent activation energy, $\mathrm{E}_{\mathrm{a}}$, could be determined from the equation:

$$
\mathrm{R}_{\mathrm{w}}=\mathrm{k} \exp \left(-\mathrm{E}_{\mathrm{a}} / \mathrm{RT}\right)
$$

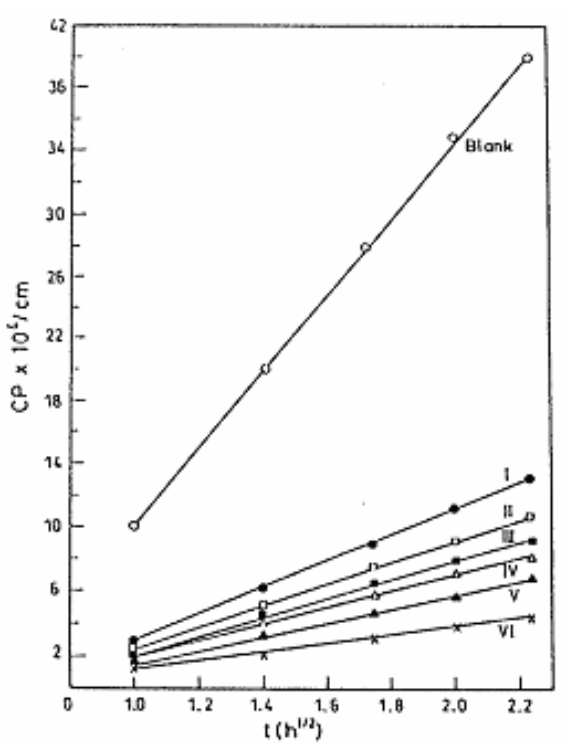

Figure 11. Plots of the corrosion penetration versus $\mathrm{t}^{1 / 2}$ for $\mathrm{C}$-steel in $2 \mathrm{M} \mathrm{HCl}$ in the absence and in the presence of $10^{-3} \mathrm{M}$ of inhibitors.

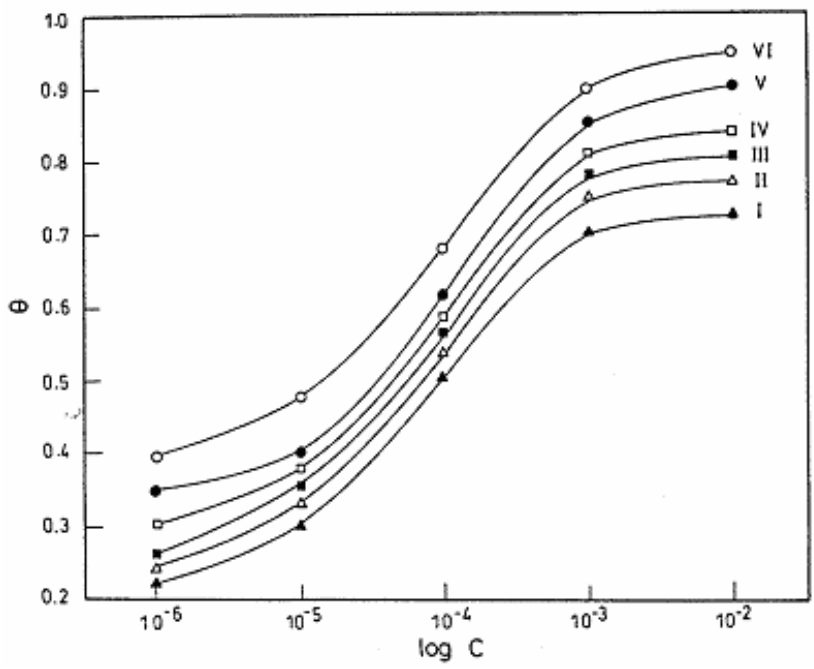

Figure 12. Frumkin's model of adsorption of inhibitors on the C-steel in $2 \mathrm{M} \mathrm{HCl}$ at 25 ${ }^{\circ} \mathrm{C}$. 
The calculated values of $\mathrm{E}_{\mathrm{a}}$ are: $23,28.6,32.5,37.22,42,46.8,50.6 \mathrm{~kJ} / \mathrm{mol}$ for the pure acid and organic compounds (I-VI), respectively.

Ideally, a corrosion inhibitor is a substance that increases the activation energy of the corrosion process. This is clear from the obtained values of $E_{a}$ in a pure acid and in the presence of the investigated inhibitors. This means that the energy barrier for the corrosion reaction increases in the presence of these additives, where the corrosion reaction will be further pushed to surface sites that are characterized by higher values of $E_{a}$. This indicates that carbon steel corrosion occurs at the uncovered part of its surface. The value of $E_{a}$ for the investigated inhibitors increases according to the order: I $<$ II $<$ III $<$ IV $<$ V $<$ VI. This order is the same as that of the inhibition efficiency, $\mathrm{I} \%$, of the investigated compounds.

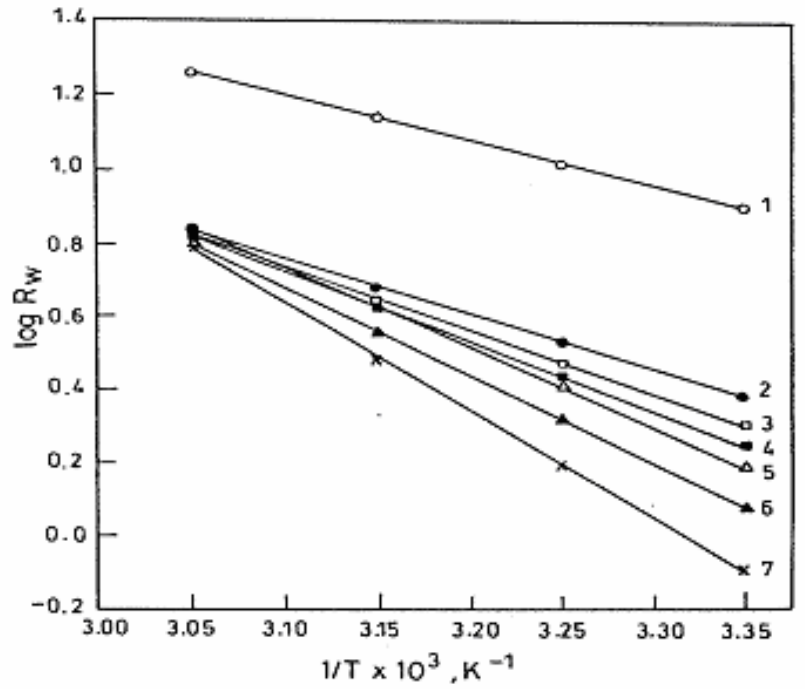

Figure 13. Arrhenius plots for $\mathrm{C}$-steel in $2 \mathrm{M} \mathrm{HCl}$ in the absence and in the presence of $10^{-3} \mathrm{M}$ of inhibitors.

On the other hand, in the discussion of the activation energies, some attention should be given to the fact that the inhibition effect is due to the increase of surface coverage by the inhibitor. Thus, the characteristics, kinetics and thermodynamics of corrosion process itself (in sites where corrosion takes place) should not be affected by the presence of the inhibitor; only the surface area available for the corrosion process is reduced.

The corrosion inhibition is due to the adsorption of the inhibitors at the electrode/solution interface. The extent of the adsorption of an inhibitor depends on the nature of the metal, the mode of adsorption of the inhibitors, and the surface conditions. Adsorption on carbon steel is assumed to take place mainly through the nitrogen atoms of amino groups and would depend on their electron density. Transfer of lone pairs of electrons on the nitrogen, oxygen, sulphur atoms to the surface to form a coordinate type of linkage is favored by the presence of vacant orbital in iron atom of low energy. Polar character of the substituents in the changing part of the inhibitor molecule seems to have a prominent effect on the electron density of the molecule. The order of increasing 
inhibition efficiency of the aminopyrimidine derivatives is: $\mathrm{I}<\mathrm{II}<\mathrm{III}<\mathrm{IV}<\mathrm{V}$ $<$ VI.

In organic compounds differing in the functional donor atoms (other factors being equal), the order of corrosion inhibition is usually: $\mathrm{S}>\mathrm{N}>\mathrm{O}$, which is the reverse order of electronegativity. Sulphur compounds are better corrosion inhibitors than their nitrogen and oxygen analogues, because the $\mathrm{S}$-atoms are less electronegative than $\mathrm{N}$ and $\mathrm{O}$-atoms, and being thus the more efficient electron donor forming chemisorptive bond. Compound (VI) is the most efficient inhibitor for the corrosion of carbon steel in $2 \mathrm{M} \mathrm{HCl}$ solution; this is most probably due to the presence of three adsorption centers: one of mercapto group $(-\mathrm{SH})$ and two of amino group $\left(-\mathrm{NH}_{2}\right)$, (one sulphur atom and two nitrogen atoms), leading to an increase of the electron density on the inhibitor molecule and hence an increase in the inhibition efficiency of the compound. Compound (V) comes next to compound (VI), since this compound (V) contains three nitrogen atoms as adsorption centers (instead of two $\mathrm{N}$-atoms and one $\mathrm{S}$-atom in compound VI). Compound (IV) comes next to compound (V), since this compound (IV) contains three active adsorption centers (two $\mathrm{N}$-atoms and one $\mathrm{O}$ atom), state of which decreases the electron density on the inhibitor molecule. Compound (III) comes after compound (IV): this is due to the presence of only two $\mathrm{N}$-atoms as adsorption centers in the molecule. Compound (II) comes next to compound (III): this is due to the presence of two O-atoms as adsorption centers in the molecule. Compound (I) is the least effective inhibitor in this series of compounds, because it contains only one $\mathrm{N}$-atom as an adsorption center. It can indicate that the inhibitory effect of the organic molecule depends on the number and nature of the adsorption centers in the inhibitor.

\section{Conclusions}

1- Aminopyrimidine derivatives act as corrosion inhibitor for carbon steel in $2 \mathrm{M}$ $\mathrm{HCl}$ solutions.

2- The inhibitory effect of these compounds is due to the presence of $\mathrm{N}$-atoms, $\mathrm{O}$-atoms and $\mathrm{S}$-atoms in the molecules acting as adsorption centers on the metallic surface. The electron density on the compound greatly affects its inhibitory effect.

3- The adsorption of the investigated compounds onto carbon steel obeyed Frumkin's adsorption isotherm.

4- The inhibition efficiency of the investigated compounds decreases with the decrease of temperature.

5- The presence of these inhibitors in the aggressive media increases the value of the activation energy of corrosion.

6- There is agreement between the results obtained by different techniques.

\section{References}

1. B. Sathianandhan, K. Balakrishnan, N. Subramanyon, Br. Corr. J. 5 (1970) 270.

2. E. Zucchi, G. Tranbanelli, G. Brunero, Corros. Sci. 33 (1992) 1135.

3. J. Uhrea and K. Aramaki, J. Electrochem. Soc. 138 (1991) 3245. 
4. J.O’M. Bockris, B. Yang, J. Electrochem. Soc. 138 (1991) 2237.

5. G. Banerjee, S.N. Malhotra, Corrosion 48 (1992) 10.

6. G. Schmitt, Br. Corros. J. 19 (1984) 165.

7. G. Lewis, Corros. Sci. 22 (1982) 579.

8. S. Rengamani, T. Vasudevan, S.V.K. Iyer, Ind. J. Technol. 31 (1993) 519.

9. M. Ajmal, J. Rawat, M.A. Quraishi, Brit. Corros. J. 34 (1999) 220.

10. F. Bentiss, M. Lagrenee, M. Traisnel, J.C. Hornez, Corros. Sci. 41 (1999) 789.

11. F. Bentiss, M. Traisnel, M. Lagrenee, Brit. Corros. J. 35 (2000) 315.

12. K.F. Khaled, N. Hackerman, Electrochim. Acta 48 (2003) 2715.

13. M.T. Saeed, SK.A. Ali, S.U. Rahman, Anti-Corros. Methods and Materials 50 (2003) 201.

14. M. Lagrenee, B. Mernari, M. Bouanis, M. Traisnel, F. Bentiss, Corros. Sci. 44 (2002) 573.

15. S.T. Keera, Anti-Corros. Methods and Materials 50 (2003) 280.

16. A. Popova, E. Sokolova, S.Raicheva, M. Christov, Corros. Sci. 45 (2003) 58.

17. T. Tsuru, S. Haruyama, Bashoku Gijutsu, J. Japan. Soc. Corros. Engng. 27 (1978) 573.

18. A.B. Brown, J. Electrochem. Soc. 134 (1987) 2506.

19. B. Hammouti, A. Aouniti, M. Taleb, M. Brighli, S.Kertit, Corros. Sci. 51 (1995) 411. 